\title{
Support for current patients infected addicts
}

\author{
Karine Bartolo, ${ }^{*}$ Pascal Auquier \\ From Abstracts from International Symposium HIV and Emerging Infectious Diseases 2014 \\ Marseille, France. 21-23 May 2013
}

In 2013, the network supported 282 addict patients. 121 patients including 24 women are infected with HIV or HCV and 109 have hepatitis C. All have a substitution of Buprenorphine or Methadone treatment. 110 / 121 patients have a general practitioner and $101 / 121$ have a regular pharmacist. (figure1).

25 patients are cured of hepatitis $\mathrm{C}$ out of 47 who received treatment and 14 patients are cured spontaneously without treatment. Among 121 patients, 16 have already been hospitalized in psychiatry. 45 patients have a psychiatric co-morbidity and 40 are treated for this disease. (figure 2).

Very few patients have less than 200 CD4. (figure 3).

Most patients were followed up since 2008. (figure 4).

\section{Conclusion}

Addict patients take subscribe to a course of complex care, and often long term. They are often supported in a complementary manner by the city and the hospital. Their immune status for seropositive patients of HIV are often above $200 \mathrm{CD} 4$. They often have an associated psychiatric comorbidity for which they receive treatment. When the

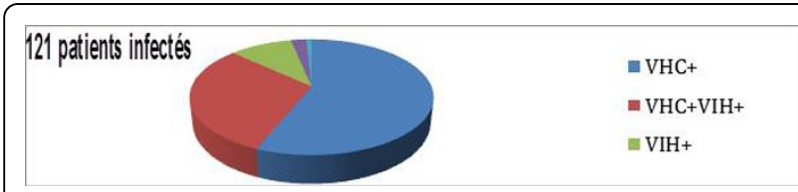

Figure 1

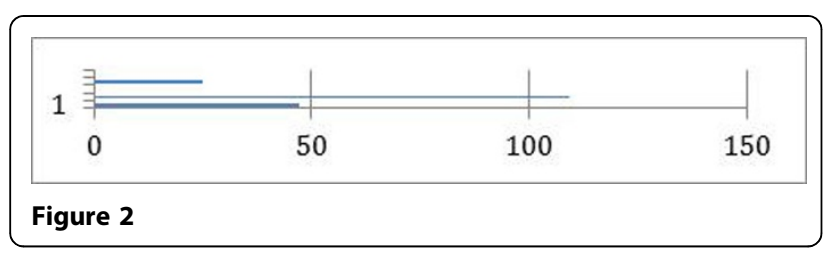

Aix-Marseille University, La Timone Faculty, Addiction Center, Marseille, France

C Biomed Central

o 2014 Bartolo and Auquier; licensee BioMed Central Ltd. This is an Open Access article distributed under the terms of the Creative Commons Attribution License (http://creativecommons.org/licenses/by/4.0), which permits unrestricted use, distribution, and reproduction in any medium, provided the original work is properly cited. The Creative Commons Public Domain Dedication waiver (http://creativecommons.org/publicdomain/zero/1.0/) applies to the data made available in this article, unless otherwise stated. 